\title{
Teatro de papel - certa dramaturgia de Artur Azevedo
}

Orna Messer Levin

A dramaturgia em um ato de Artur Azevedo, considerada secundária em relação às comédias, burletas e revistas de ano, passou quase despercebida pela historiografia literária do século XX, exceção feita a uma ou outra peça com maior acolhimento junto ao público brasileiro que, tendo retornado diversas vezes aos palcos, despertou alguma atenção e mereceu comentários passageiros nos estudos sobre o teatro oitocentista. Exemplar nesse aspecto é o famoso ato Amor por Anexins, sempre lembrado, de passagem, como a primeira criação bem sucedida do jovem comediógrafo, que a escreveu por volta de 1870, quando ainda residia em S.Luís do Maranhão. A peça foi representada com certa freqüência durante o século XIX e tem sido retomada até os dias de hoje por elencos consagrados, como o do grupo Tapa, e também por estudantes e iniciantes, que trazem propostas de renovação poética com versões para espetáculo de rua ${ }^{1}$.

A considerar pelas montagens recentes de Amor por Anexins, apesar de reduzido, não chega a ser desprezível o número de espetáculos que se debruçam sobre as peças curtas de Artur Azevedo. Sem dúvida maior do que as esporádicas, por que não dizer, raras montagens de comédias e revistas de sua pena. Compreende-se que algumas das peças longas tenham perdido atualidade e não suportem releituras modernas, em razão das características excessivamente literárias que lhes restringe demais o potencial cênico, no caso das comédias ditas "sérias", ou devido ao grande aparato que, no que se refere às revistas, dificulta e encarece a produção. O crítico Sábato Magaldi chegou a afirmar que a maioria das peças de Artur Azevedo não seria capaz de resistir ao teste dos palcos (MAGALDI, 1997). Em relação a estas, a vantagem das peças em um ato talvez se encontre na facilidade da comunicação com o gosto popular e na simplicidade dos efeitos. Sem pretensões elevadas e em busca da clareza nas mensagens, as peças curtas se valem da economia característica do gênero: poucas cenas, poucas personagens, cenário e figurino restritos.

Um outro aspecto a ser levado em conta nesse paralelo é a histórica oferta de publicações impressas, que favoreceram a disseminação da prática de leitura de textos teatrais em um ato, bastante incomum nos dias que correm, por meio das quais se preservaram algumas dessas pecinhas de Artur Azevedo. Diferentemente do que ocorreu com as revistas de ano, muito populares, porém, raras vezes editadas, visto que seu atrativo maior fosse o próprio espetáculo, cuja teatralidade se associava aos efeitos cênicos inesperados e à agilidade dos movimentos físicos, a dramaturgia em um ato dependia menos dos recursos do palco e, por isso, podia ser apreciada com facilidade também no ato da leitura. Para uns, a possibilidade de revisitar as cenas assistidas no teatro estimulava o consumo e aquisição constante de textos impressos. 
Já para aqueles que não pudessem estar presentes às representações, a leitura de peças teatrais oferecia a oportunidade do lazer recolhido e da fruição da cena por meio da imaginação. E para os dramaturgos podia significar um rendimento extra, somado aos resultados da bilheteria.

Assim, não surpreende que a dramaturgia breve ganhasse estampa em diversos formatos editoriais de ampla circulação no século XIX. Peças em um ato encontravam-se disponíveis nas páginas de publicações periódicas, revistas ilustradas, brochuras avulsas e seletas encadernadas, como decorrência do aquecido comércio livreiro que se mantinha ativo na esteira das sucessivas montagens teatrais. Em parte, esse fenômeno se explica pelo caráter circunstancial das peças curtas, concebidas sob o impulso das oportunidades do momento. A motivação para redigi-las podia nascer da adesão do escritor a determinado debate político, como no caso da temática abolicionista presente em $O$ Liberato (1881); podia ser suscitada pela iniciativa do dramaturgo em homenagear artistas em noite de seu benefício, como fez Artur Azevedo para presentear Isolina Monclar que protagonizou a estréia de Uma Noite em Claro (1884); ou vir do desejo de retomar em chave cômica algum título que estivesse em cartaz, a exemplo do que ocorreu em Amor ao pêlo (1897), a versão paródica que ele redigiu a partir da estréia de Pelo Amor, de Coelho Neto. ${ }^{2}$

Uma vez motivadas pelas circunstâncias de seu surgimento, as peças curtas que chegavam à ribalta respondiam a um propósito imediato do qual se tornavam cúmplices os espectadores. Isso, porém, não significa que o alcance da mensagem dramatizada se esgotasse no evento de estréia ou mesmo nas representações futuras. Esta dramaturgia passaria do palco à página, para utilizar expressão cara a Roger Chartier (2002, p.69) seguindo a lógica de um mercado de bens culturais que se expandia no Brasil e se alimentava da curiosidade dos leitores pelos assuntos teatrais. $\mathrm{O}$ circuito de produção centrado no divertimento teatral articulava o empreendimento comercial do espetáculo, em torno de um grupo ou companhia, com a posterior publicação que os jornais ou casas editoriais facultavam, potencializando a recepção dos conteúdos veiculados de acordo com as normas do gênero e as convenções dramáticas. O original de O Liberato que veio à cena no Teatro Lucinda, em 16 de setembro de 1881, circulou na Revista Brasileira, núcleo de intelectuais simpáticos à causa republicana e abolicionista, no primeiro dia de novembro. Logo após a primeira apresentação do ato cômico $A$ mascote na roça no Teatro Recreio Dramático, ocorrida em 15 de maio de 1882, Artur Azevedo publica o texto nas páginas de Gazetinha. ${ }^{3}$ Paralelamente, as várias edições de Amor por Anexins (1870) ${ }^{4}$ nas coleções de teatro popular, à venda no Brasil e em Portugal, ilustram a presença freqüente da dramaturgia curta no mercado livreiro, o que igualmente se pode observar na inclusão de Uma véspera de Reis (1875) entre os textos reunidos em Horas de Humor (1876) e, mais tarde, no volume póstumo Vida Albeia (1929). ${ }^{5}$

Vale dizer que a familiaridade dos leitores do século XIX com os gêneros dramáticos breves decorre do lugar reservado às obras em ato único na programação dos teatros. Concebidas como parte de um conjunto maior, que se ajustava ao tempo e à dimensão de um espetáculo noturno longo, as peças curtas eram apresentadas 
nos intervalos dos atos de uma peça principal ou ao final desta, junto a composições musicais e bailados. ${ }^{6}$ Deriva de esse lugar intervalar que ocupavam na programação a sua designação mais comum como entreatos ou intermédios, embora nos impressos se possa encontrar indicações de gêneros diversos, tais como "conto-comédia" no caso do ato cômico Como me diverti, "comédia" na referência à peça O oráculo, "farsa" na designação da primeira edição de As sobrecasacas e "diálogo cômico" no texto em versos de Confidências, incluído no volume Contos em verso que a editora Garnier publicou. As designações variáveis revelam o exercício de uma diversidade de subgêneros literários em que as formas dialogadas pertencentes à cultura teatral do período são utilizadas com freqüência.

Nas representações dos espetáculos teatrais, as companhias que montavam traduções adaptadas de peças estrangeiras incorporavam ao seu repertório peças curtas de autores nacionais. ${ }^{7}$ Já as trupes estrangeiras em excursão pelo país tinham por hábito homenagear escritores locais, levando à cena títulos de sua autoria vertidos para a língua da companhia, geralmente o francês ou o italiano. Fora do circuito comercial, peças breves encontravam o acolhimento entusiasmado dos grupos amadores. E numa esfera mais reservada, os saraus domésticos também abrigavam em sua programação artística a execução de trechos musicais, declamação de poesias, cantos e leitura dramatizada de peças em um ato.

Acomodada à cultura teatral brasileira do século XIX, a dramaturgia em um ato integra um padrão de divertimento misto, tanto na esfera pública quanto priva$\mathrm{da}$, que adentra os primeiros anos do século XX e antecede o processo de especialização artística, do qual resultaram os espetáculos independentes de música, teatro e dança. No contexto dessa programação mista, as peças curtas se destinam ao entretenimento leve, com a finalidade de ajudar a distrair o público durante a troca de figurinos e cenários de peças longas ou contribuir para criação de uma atmosfera alegre e descontraída no encerramento da noite. $O$ tom predominantemente cômico acaba por reforçar o aspecto risonho e inconseqüente dessa dramaturgia.

\section{Os atos musicados}

Amorpor Anexins, a primeira das diversas peças em um ato que Artur Azevedo criou entre 1870 e 1907, segue a trilha da hilariedade inocente, que explora o jogo com a sabedoria popular em contraponto com a seriedade contida das peças-provérbio, ao gosto francês, de que temos bom modelo no teatro de Machado de Assis. Simples e despretensiosa, esta peça focaliza o recorrente tema amoroso, herdeiro da tradição vicentina, envolvendo um velho ridicularizado pelo cortejo a uma jovem senhora. Lembra, nesse particular, o Auto da Sibila Cassandra, ${ }^{8}$ de Gil Vicente, em que a corte amorosa de Isaías a Cassandra organiza a fábula. Na peça de Artur Azevedo, a jovem Inês, uma costureira viúva, vê-se assediada por outro Isaías, também velho e um tanto impertinente, que por meio de oferendas e promessas insiste na conquista amorosa. Se o tema é antigo e a situação conhecida, Artur Azevedo 
inova na feição cômica do protagonista, pois atribui ao tipo já tradicional do homem maduro apaixonado uma maneira singular de se expressar por meio de adágios e ditos populares. ${ }^{9} \mathrm{O}$ título da peça - Amor por Anexins - sugere o direcionamento da paixão que é alvo de ridículo. Isaías só fala por meio de anexins. Aceitar a proposta de casamento implica apreciá-los. Mas, fazendo referência a tal singularidade do protagonista, a peça evidencia que apesar de toda a sensatez e sabedoria acumuladas nos provérbios e ditados populares que Isaías usa, o que torna possível o casamento, ao final, é tão somente a decisão interesseira da jovem viúva.

Inês: Mesmo por já estar no caso de me dar conselhos, é que o não quero para marido.
Isaías: Se eu fosse jovem, não me havia de aceitar, por estar no caso de os receber. Preso
por ter cão e preso por não ter!
Inês: Não desejo enviuvar de novo...
Isaías: Vaso ruim não quebra...
Inês: Desengane-se, senhor: não são os seus ditados que me hão de fazer mudar de
resolução! Oh!
Isaías: Talvez façam, talvez! ... Devagar se vai ao longe... muito tolo é quem se cansa...
Menina, antes só do que mal acompanhado... Olhe que o pior cego é aquele que não
quer ver... (AZEVEDO, 1995)

A leveza do jogo cômico construído no plano da linguagem, que surge entretecida pelo senso comum de provérbios lançados pela boca de um senhor inconvenientemente sábio, resulta também da forma como o conflito de interesses chega ao ponto de reviravolta. Inês, depois de receber uma carta do jovem noivo rompendo o compromisso que mantinha com ela por ter vislumbrado uma chance de consórcio mais vantajoso, decide considerar a corte de Isaías, a quem rejeitara de início, sob a condição de que ele aceite o desafio de ficar por algumas horas sem usar um anexim. O desafio que Inês lança ao pretendente não é cumprido, mas abre o caminho para uma solução feliz, o que convém a toda peça do gênero.

Amor por Anexins, como disse, é simples e graciosa, embora já anuncie a habilidade do dramaturgo em sustentar os diálogos dramáticos, que funcionam aqui como apoio para a condução de um enredo conhecido de antemão pelo público. $\mathrm{O}$ texto segue o modelo da farsa ligeira, descendente do entremez ibérico que esteve presente nos palcos brasileiros em criações lusitanas e foi muitíssimo lido nos impressos de cordel. Sabe-se que nossa comédia de costumes nasceu, pelas mãos de Martins Pena, da acomodação de entremezes lusitanos aos tipos e situações locais (ARÊAS, 1987). Os elementos da hilaridade popular de antigos entremezes, que se encenavam em ruas e feiras, deixaram marcas no uso de uma linguagem dramática que se aproximou da fala cotidiana e por vezes chegou a produzir expressões tão rudes quanto aquelas típicas de peças anônimas. À medida que a farsa ingressou nos teatros e domicílios, operou-se uma depuração no linguajar mais chulo, em favor de uma comicidade leve e brejeira, extraída de situações dramáticas em que o ridículo surge menos da vulgaridade dos termos e piadas proferidas pelos tipos cômicos do que de ações ilustrativas do intuito satírico. 
Amor por Anexins, como tantos entremezes, se estrutura em um ato único e contém sete cenas que evoluem no dinamismo e agilidade das falas, ora em monólogos, ora em diálogos. Influenciado pela voga do teatro musicado que prevaleceu em toda a segunda metade do século XIX, Artur Azevedo acrescentou às falas e apartes das personagens alguns recitativos e cantos. A ação da peça se passa na casa de Inês, tendo como marcação temporal a chegada do pretendente, sua saída ao armarinho para atender ao pedido de ajuda dela, durante o qual chega a carta de rompimento do noivo, e o seu regresso com os aviamentos para concluir com a felicidade do aceite final. De acordo com a convenção musical da época, Inês canta a copla de abertura, na primeira cena, em que ela pondera sobre o insistente pedido de casamento de Isaías. Na sexta cena, após a decepção com o jovem noivo, canta um recitativo sobre o poder do dinheiro, diante do qual ela, desolada, afirma: "caem virtudes e se exaltam vícios!”. A última cena, que se inicia com a chegada de Isaías de volta do armarinho, dá vez ao canto de exposição do seu sonho de vida conjugal, por fim correspondido por Inês, a quem se une para cantar a copla final em declaração de amor. O casal encerra o ato com um simpático pedido de palmas para os atores e para o autor.

A entoação de cantos individuais e corais na organização estrutural da peça é, sem dúvida, revelador da influência que o teatro musicado, em especial a opereta, exerceu sobre a dramaturgia breve. Na opereta, o acompanhamento musical é constitutivo do próprio gênero, ao passo que os cantos e danças na dramaturgia em um ato, desde a sua origem ibérica, ocorriam predominantemente na cena final de encerramento. Artur Azevedo cedo incorporou as passagens musicadas, abrindo a trilha que seguiria na criação da burleta, a versão brasileira das operetas francesas.

Exemplar nesse sentido, sua segunda peça breve, Uma véspera de reis, que estreou em 1875 em Salvador, aborda a temática amorosa tendo como pano de fundo as comemorações da festa popular no dia de Reis, cuja manifestação mais típica são as danças do rancho. A intriga amorosa em torno dos jovens enamorados envolve relações familiares e é retratada no âmbito da vida doméstica em Salvador, no qual as mulheres se ocupam dos afazeres da cozinha, preparando doce de araçá, enquanto os homens tratam de questões relativas à propriedade da terra e o moleque José, escravo cativo, pede licença aos senhores para participar das folias do rancho. Organizada em 20 cenas, essa segunda peça de Artur Azevedo cruza mais fios em redor do tema do matrimônio, abordando assuntos da vida cotidiana, como o progresso da cidade de Salvador, onde já há bondes, e fazendo o retrato dos costumes populares, da vida boêmia estudantil, da fofoca na vizinhança, além de apresentar uma mentalidade liberal em relação ao papel da mulher no casamento e na família. Por conter mais cenas, a estrutura da peça incorpora oito entradas musicais, sendo a copla inicial cantada, na segunda cena, pelo moleque José, exibindo sua astúcia e vivacidade. $\mathrm{O}$ escravo se faz cúmplice dos amantes, como não poderia deixar de ser, e canta com Alberto, o pretendente de Emília, um Duetino. Seguem-se cantos em coro, dueto e trio, até o encerramento do ato com a entrada do rancho, trazido pelo moleque José à casa de Reis, seu patrão, que é invadida pela música forte e pelas danças do povo. 
Ambas as peças da década de 1870 até aqui mencionadas revelam o apego de Artur ao modelo da longa tradição do entremez e da farsa popular, que conjuga os diálogos falados aos movimentos gestuais da dança e instrumentais da música acompanhada de cantos. Esse modelo há muito abandonado pelos dramaturgos dedicados ao teatro burguês "sério" se conserva no espírito e no gosto da audiência, à qual Artur soube agradar como nenhum outro, o que contribuiu para o enorme sucesso de suas burletas.

\section{Ato sem música - os limites do cômico}

A transferência de Artur Azevedo para o Rio de Janeiro, em 1873, onde a campanha abolicionista ganhava simpatizantes no meio intelectual, favoreceu o engajamento na imprensa diária e repercutiu na produção teatral da década seguinte, a exemplo do que ocorrera com seu irmão Aluísio Azevedo, autor de O mulato, que recebeu boa acolhida na capital, na década de 1880. Entusiasmado com a causa antiescravocrata, Artur Azevedo escreveu a peça em um ato $O$ Liberato, que subiu à cena pela primeira vez no teatro Lucinda, em 1881. Nela o escravo, ironicamente designado como Liberato, não tem voz, ao contrário da peça Uma véspera de reis, encenada em Salvador, em que o moleque não só participava da ação com uma ingenuidade inocente, como cantava em destaque, logo na primeira cena. Na cena carioca, porém, o moleque cativo é apenas mencionado como “o negro” preguiçoso.

A situação dramática central novamente é doméstica e decorre do fato de o escravo estar adoecido, dando pretexto para que o tratamento desumano a que o submete D. Perpétua, sua ama, se mostre cheio de preconceitos e autoritário, o que vem provocar a revolta do sobrinho Ramiro, jovem amanuense enamorado de Rosinha, a filha dela. O jovem casal de enamorados conta com o apoio paterno, mas a mãe, D. Perpétua, dá preferência ao casamento com Sr. Moreira, fazendeiro conservador de 50 anos, cujo interesse em Rosinha, depois, revela ser apenas em função da herança que ela receberá do Major Gaudêncio, seu amigo.

O advogado Lopes, pai de Ramiro, é irmão de D.Perpétua, que com ele herdou há 20 anos o único cativo da família. Liberais e abolicionistas, pai e filho, Lopes e Ramiro, enfrentam a resistência severa de D.Perpétua, que não aceita os quinhentos mil réis oferecidos em paga pela liberdade do escravo. Esse conflito de que depende a felicidade do jovem casal se desata com a abertura do testamento do Major, pois este condiciona a doação da herança ao casamento de Rosinha com Ramiro Lopes.

A condição de cativo expõe-se em cena como uma sentença imutável da qual só pode resultar a morte do escravo adoentado, que é anunciada no desfecho, motivando ironicamente o pesar de D. Perpétua, não pelo falecimento do rapaz, mas por não ter recebido os 500 contos oferecidos pelo seu irmão. O drama de temática libertária evidentemente não poderia ser encenado ao som festivo da farsa, portanto, há uma notável mudança de uso de linguagem, um câmbio para a sobriedade da denúncia contra a injustiça do aprisionamento, da opressão, do confinamento a que a propriedade e o dinheiro submetem o homem. 
Para o propósito da reflexão que estou tentando desenvolver aqui, vale observa mais atentamente que em $O$ Liberato a decisão de Ramiro, o rapaz enamorado de Rosinha, em abraçar a causa anti-escravocrata ocorre após uma noite de entretenimento no Teatro, que ele como jovem boêmio freqüenta com assiduidade. Após assistir a uma representação dramática, sai entusiasmado do teatro, convencido da necessidade de lutar pela abolição.

Ramiro: Prima!

Rosinha: Por que não vieste há mais tempo?

Ramiro: Hoje quase morri!

Rosinha: Credo!

Ramiro: De entusiasmo!

Rosinha: Respiro.

Ramiro: Que talentos! Que idéias! Que eloqüência! Que mocidade!...

Rosinha: Nunca te vi assim!

Ramiro: Pudera! Se eu nasci hoje! Até agora, tu, só tu enchias o meu coração; doravante tens uma rival: a liberdade! É que nunca me lembrei de que um milhão e meio de homens amargam neste país a sorte mais bárbara, o mais horrível destino! Oh! viva a liberdade, formosa deusa que ilumina o mundo!

Chamo a atenção para essa fala a fim de ressaltar o papel político do teatro na divulgação do pensamento liberal no Brasil. A propagação dos ideais libertários ocorre nas casas de teatro, daí a transformação processada em Ramiro após uma noite de prazer com amigos boêmios. É preciso assinalar ainda o impacto da recriação discursiva que um texto dramático promove no palco. O teatro, enquanto arte de representação verbal e gestual, consiste em um lugar de re-elaboração de discursos enunciados na sociedade. Uma vez inseridos nas falas das personagens tais formações discursivas retornam ao meio social, intervindo e afetando a audiência, num circuito de re-significação de sentidos que tem um marco histórico preciso, o momento da enunciação cênica. A recepção das enunciações cênicas por parte do público, isto é, a recepção das formações discursivas que as falas das personagens citam, produz uma situação histórica, um presente empírico, por assim dizer único, no qual os discursos são mobilizados pela ficção e, ao mesmo tempo, re-significados pela recepção daquele que assiste ao espetáculo. Isso faz ver que a citação, a repetição ou a menção a termos, expressões, temas ou idéias produz no teatro uma metaenunciação de discursos socialmente estabelecidos.

É o caso da personagem Ramiro, que reproduz um discurso abolicionista e ao mesmo tempo retrata o lugar social em que esse discurso circula, a saber, o teatro. $\mathrm{O}$ que a personagem nos mostra é o curioso deslocamento do discurso liberal no Brasil, disseminado primeiro no espaço fechado dos teatros, no qual colheu adeptos entre os freqüentadores, para só depois vir às ruas. $O$ que se observa nessa pequena peça de Artur Azevedo, então, é uma imagem do teatro tomado como instrumento discursivo de persuasão política e ação transformadora. Uma imagem, contudo, mais romântica do que crítica, na medida em que o moralismo do encerramento do ato não permite alternativas para a extinção do trabalho escravo. $O$ jovem escravo mor- 
re antes de receber a alforria e o dinheiro de seu pecúlio serve apenas para pagar um enterro mais digno.

Ora, o teatro para o qual Artur Azevedo trouxe energia e vitalidade renovadoras ainda estava longe do teatro político do século XX. Os diálogos encenados em suas peças curtas limitavam-se a apontar alguns usos de linguagem e formações discursivas que viriam a ser pouco depois a chave do teatro moderno em um autor como Brecht, que soube se aproveitar da paródia para buscar o efeito de estranhamento. Artur Azevedo, por sua vez, preso ao modelo e às convenções do teatro burguês, embora tomasse o teatro como agente desencadeador da consciência social e fosse sensível aos efeitos das palavras, manteve-se dentro dos limites dados à personagem Ramiro, incapaz de converter suas falas em instrumento de ação. $\mathrm{Na}$ obra de Artur Azevedo, o teatro permanece confinado em si mesmo, enquanto dado de citação intertextual, paródia jocosa, como em Amor ao pêlo, ou brincadeira divertida, como na alegre versão que criou para a opereta de Edmond Audran, $A$ mascote na roça. Subjugadas à condição de divertimento leve, suas peças em um ato nos ajudam a entender as razões da ausência daquela dimensão libertadora que os usos discursivos do teatro moderno nos ensinaram a apreciar.

\section{Notas}

${ }^{1}$ Comemorando 20 anos de suas atividades, o Grupo Tapa, do diretor Eduardo Tolentino de Araújo, montou recentemente três atos de Artur Azevedo (Amorpor Anexins, Uma Consulta e O Oráculo) no espetáculo intitulado $A s$ viúvas. Os mesmos três atos foram apresentados no festival de Curitiba, em 2007, tendo a atriz pernambucana Hemíla Guedes no papel da viúva, papel este que em 1986, fora representado pela atriz Maria Padilha numa montagem de Luis Antônio Martinez Corrêa. Em 2006, o grupo Teatro Contratempo levou ao palco do Teatro Brigadeiro (São Paulo) Amorpor Anexins e o ato A pele do lobo, raramente visto em cena, como parte do espetáculo Comédia $3 \times 4$. E desde 2001, o grupo de teatro Cirquinho do Revirado, de Criciúma (SC), contando com o apoio do "Em Cena Brasil", da Funarte, vem apresentando a sua versão para espetáculo de rua da peça Amor por Anexins, com a qual, após apresenta-se no $12^{\circ}$ Festival de Curitiba, ganhou diversos prêmios em Florianópolis, Minas Gerais, Rio de Janeiro e São Paulo. Em setembro de 2008, o Grupo Dionisos, de Joiville (SC) representou outra versão popular desta peça no Festival de Teatro de Rua Stenio Garcia.

${ }^{2}$ Agradeço a Danielle Crepaldi pelas informações detalhadas que me forneceu a respeito da polêmica teatral envolvendo Coelho Neto e Artur Azevedo a propósito da estréia de Pelo Amor.

${ }^{3}$ Gazetinha, Rio de Janeiro, 19 a 27 de maio de 1882.

${ }^{4}$ Publicada no Rio de Janeiro pela casa Serafim José Alves, ganhou duas edições paulistas sob o selo de Cunha \& Irmãos, outras duas portuguesas na série intitulada Biblioteca Dramática Popular que o editor Francisco Franco organizou e duas na Coleção de Peças para Salas e Teatros Particulares, além da publicação na revista da Academia Brasileira de Letras, em 1931, a que se seguiram a da revista da Sociedade Brasileira de Artes Teatrais (SBAT), em 1955, e a do volume de Teatro Completo organizado por Antonio Martins.

${ }^{5}$ Azevedo, Artur. Horas de Humor III. Rio de Janeiro: Brown \& Evaristo, 1876. Azevedo, Artur. Vida Alheia. Freitas Bastos, 1929.

${ }^{6}$ A Gazeta de Notícias informa, por exemplo, que o espetáculo da ópera cômica O Sino do Eremiterio que a companhia Souza Bastos apresenta no teatro Príncipe Imperial, de 01 a 06 de janeiro de 1885, é composto das seguintes partes: $1^{\mathrm{a}}$. parte: Nhô Quim; $2^{\mathrm{a}}$. parte: Brilhante Intermédio; $3^{\mathrm{a}}$. parte: Uma noite de carnaval; $4^{\mathrm{a}}$. parte: Outro Intermédio; $5^{\mathrm{a}}$. parte: Os trinta Botôes. 
${ }^{7}$ Em janeiro de 1880, a peça Amor por Anexins, de Artur Azevedo, foi apresentada no teatro Recreio Dramático, no Rio de Janeiro, após a comédia em 3 atos Moços e Velhos.

${ }^{8}$ Gil Vicente Auto da Sibila Cassandra. Trad. Alexandre Soares Carneiro e Orna Messer Levin. São Paulo: Cosac \& Naify, 2007.

${ }^{9}$ Nota sobre possível inspiração de Artur em outra peça.

\section{Bibliografia.}

ARÊAS, Vilma. Na tapera de Santa Cruz. São Paulo: Martins Fontes, 1987.

AZEVEDO, Artur. Teatro de Artur Azevedo. (Org. estabelecimento de texto. Antonio Martins de Araújo), Rio de Janeiro: Funarte/Ministério da Cultura, 1995.

. Horas de Humor III. Rio de Janeiro: Brown \& Evaristo, 1876.

. Vida Alheira. Freitas Bastos, 1929.

MAGALDI, Sábato. Panorama do teatro brasileiro. $4^{a}$ ed. São Paulo: Global, 1997.

PAVIS, Patrick. Dicionário de Teatro. São Paulo: Perspectiva, 2003.

VICENTE, Gil. Auto da Sibila Cassandra. (Trad., apresentação, notas, Alexandre Soares Carneiro e Orna Messer Levin). São Paulo: Cosac \& Naify, 2007. 


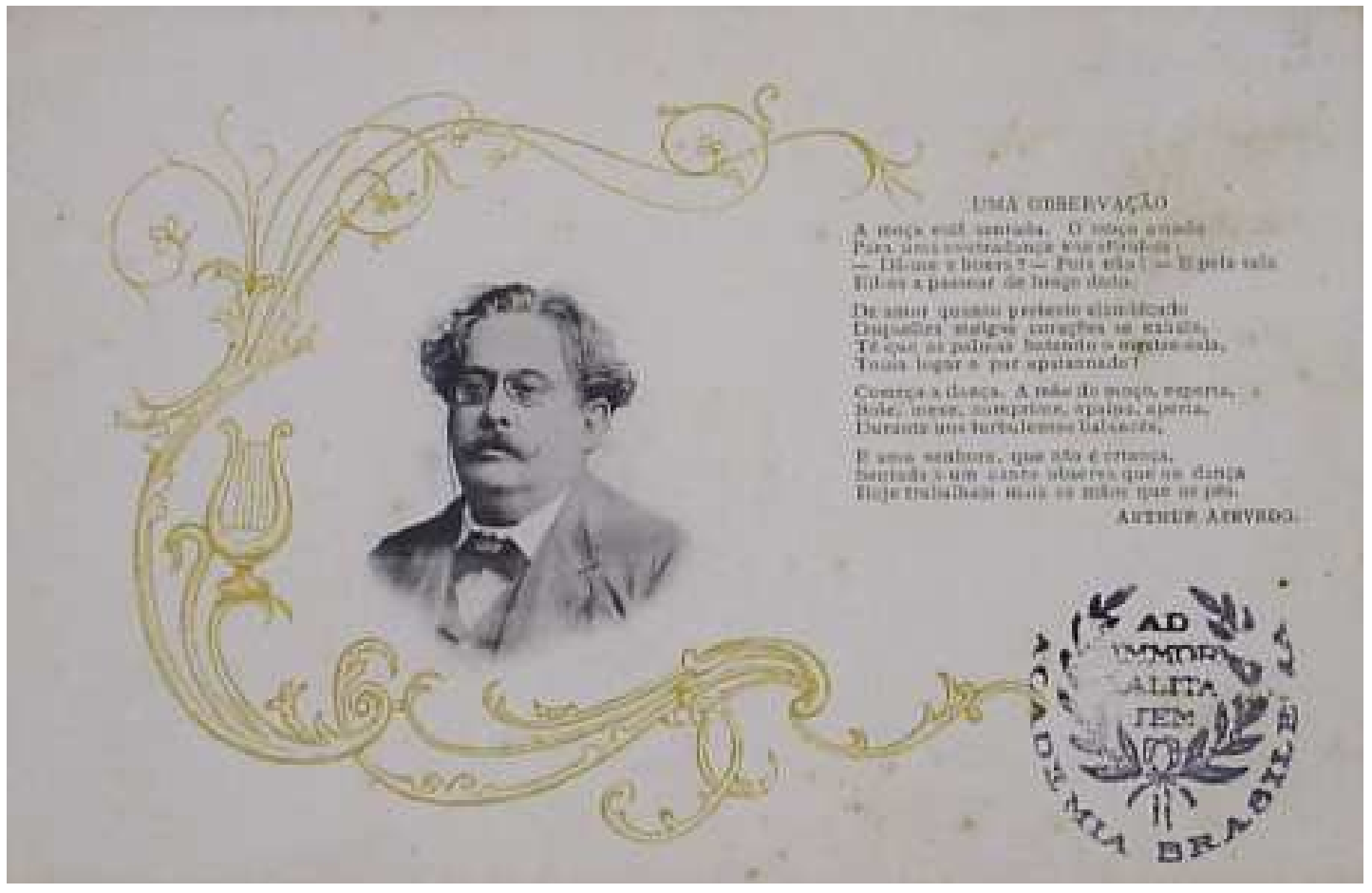

Fonte: Arquivo da Academia Brasileira de Letras 